\title{
CagA seropositivity associated with development of gastric cancer in a Japanese population
}

\author{
T Shimoyama, S Fukuda, M Tanaka, T Mikami, A Munakata, J E Crabtree
}

\begin{abstract}
Backgroundlaims-Infection with Helicobacter pylori strains possessing the cagA gene is associated with increased risk of gastric cancer of the intestinal type. The aims of this study were to investigate whether CagA seropositivity is associated with increasing risk of gastric cancer in a Japanese population that has a much higher incidence of gastric cancer than western populations.

Methods-Eighty one gastric cancer patients and 81 sex and age matched endoscopically evaluated controls were studied. Histologically, 62 cancers were of the intestinal type and 76 were early gastric cancer. Serum CagA IgG antibodies were assayed by enzyme linked immunosorbent assay (ELISA) using purified recombinant CagA protein as antigen. Polymerase chain reaction (PCR) analysis for cagA in $H$ pylori isolates $(n=80)$ showed that the CagA ELISA had a sensitivity of $83.3 \%$ (controls) and $72.5 \%$ (cancers).
\end{abstract}

Results-CagA seropositivity was $60 \%$ (49 of 81 ) in cancer patients and $44 \%$ ( 36 of 81 ) in controls. The odds ratio for the risk of cancer if CagA seropositive was 1.93 (95\% confidence interval (CI) 1.01 to 3.68 ; p < 0.05). In the $57 \quad H$ pylori positive cancer patients and their matched $H$ pylori positive controls, the odds ratio for the risk of cancer if $\mathrm{CagA}$ seropositive was 2.2 (95\% CI 1.04 to 4.65 ; $p<0.05)$.

Conclusions-These results suggest that CagA seropositivity is associated with increased risk of gastric cancer in Japanese populations.

(f Clin Pathol 1998;51:225-228)

Keywords: Helicobacter pylori; gastric cancer; CagA

Since the discovery of Helicobacter pylori, many studies have implicated infection with this bacterium in the pathogenesis of gastric diseases. Helicobacter pylori is strongly associated with atrophic gastritis and intestinal metaplasia, ${ }^{12}$ which are precursor lesions for gastric cancer, ${ }^{3}$ and infection is now a well established risk factor for the development of gastric adenocarcinoma. ${ }^{4-6}$ However, few patients with $H$ pylori infection develop gastric cancer, ${ }^{7}$ and there has been recent interest in whether specific $H$ pylori strains are associated with gastric carcinogenesis. The majority of $H$ pylori strains can be divided into one of two groups (cag positive or cag negative), based on the possession of the cytotoxin associated gene A $(\mathrm{cagA})^{89}$ and associated genes in the cag pathogenicity island. ${ }^{10}$ CagA positive strains are associated with enhanced inflammatory responses, ${ }^{11-15}$ which may increase the risk for the development of gastric cancer. Previous serological studies have also shown that infection with cagA positive strains is associated with an increased risk of developing atrophic gastritis ${ }^{1617}$ and gastric cancer. ${ }^{18}{ }^{19}$ However, few studies have assessed the relation between CagA seropositivity and gastric cancer in Japanese populations, which have a much higher incidence of gastric cancer than Western populations.

In this study, we investigated the association of CagA seropositivity with gastric cancer in a Japanese population using gastric cancer patients and sex and age matched controls who had received gastrointestinal endoscopy. We also investigated the sensitivity of the CagA enzyme linked immunosorbent assay (ELISA) in this elderly population by comparing the serological results with the possession of cagA in $H$ pylori strains obtained from the studied patients.

\section{Methods}

PATIENTS

Patients scheduled for upper gastrointestinal endoscopy for routine screening for gastric cancer at the Hirosaki University Hospital between March 1995 and August 1996 were prospectively enrolled into the study. Patients were excluded if they had received anti-ulcer agents or antibiotics during the two months before the examination, or had previous histories of gastric tumours, gastric or duodenal ulcers, and gastric surgery. All subjects provided informed consent before their endoscopy and this study was approved by the ethics committee of Hirosaki University. A total of 162 patients were entered into the study. There were 81 patients with gastric cancer (mean (SD) age 62.5 (18.9); 50 men, 31 women) and age ( \pm 3 years) and sex matched controls for each cancer patient (mean (SD) age 62.3 (19.3)). Control patients were selected randomly from those undergoing endoscopy for gastric cancer screening. Subjects on acid suppression agents and/or antibiotics were excluded. Subjects were considered to be eligible for inclusion as controls when their endoscopical diagnosis was normal or atrophic gastritis ${ }^{20}$ was present without any evidence of ulceration, erosions, or neoplasia.

In cancer patients and controls, two biopsy specimens were taken from both the antrum and the body of the stomach, one for $H$ pylori culture and another for histology. Blood was also taken from each patient and serum was
Accepted for publication 9 December 1997 
stored at $-20^{\circ} \mathrm{C}$. Biopsy specimens were taken at least $2 \mathrm{~cm}$ away from tumours, embedded in paraffin wax, and stained with both haematoxylin-eosin and Warthin-Starry stains. Specimens were examined for the presence of $H$ pylori by an experienced pathologist (MT) without knowledge of the serological results. Full histological diagnosis of the tumour type and stage was undertaken on resected gastric mucosa. The gastric cancers were classified histologically according to Lauren system. ${ }^{21}$ Early gastric cancer was pathologically diagnosed by the growth of tumour confined to the mucosa and submucosa of the stomach as described previously. ${ }^{22}$

$H$ pylori status was evaluated by serology, histology, and bacterial culture in each patient. Histologically, $H$ pylori was considered to be positive if either the antral or the corpus biopsy was positive. Patients were considered $H$ pylori positive if at least one detection method showed a positive result.

SEROLOGICAL ASSAYS

Serum samples were assayed for the presence of antibodies to $H$ pylori and CagA. $H$ pylori antibodies were measured using HELpTEST (AMARD, Kew, Victoria, Australia) according to the manufacturer's instruction. ${ }^{23}$ Previous studies have shown the sensitivity and specificity of HELpTEST in Japanese patients to be $91.2 \%$ and $81.3 \%$, respectively. ${ }^{24}$ CagA antibodies were assayed by ELISA using a recombinant fragment of CagA (kindly provided by Dr A Covacci, IRIS, Siena, Italy) as antigen, as previously described by Xiang and colleagues. ${ }^{25}$ Briefly, flat bottom 96 well microtitre plates were coated with $0.1 \mu \mathrm{g} /$ well antigen in $0.1 \mathrm{M}$ bicarbonate buffer for 24 hours at $4^{\circ} \mathrm{C}$. Plates were washed with phosphate buffered saline (PBS) containing $0.1 \%$ Tween-20 and blocked with $1 \%$ bovine serum albumin (BSA) in PBSTween for one hour at $26^{\circ} \mathrm{C}$. Serum samples diluted $1 / 75$ in $1 \% \mathrm{BSA} / \mathrm{PBS}$ were incubated in duplicate for 90 minutes at $26^{\circ} \mathrm{C}$. Following incubation with goat antihuman IgG alkaline phosphatase conjugate (Sigma, Poole, Dorset, UK) for two hours at $26^{\circ} \mathrm{C}$, bound antibodies were detected with p-nitrophenyl phosphate substrate (Sigma) at $1 \mathrm{mg} / \mathrm{ml}$ in diethanolamine- $\mathrm{MgCl}_{2}$ buffer. Positive control serum diluted $1 / 50$ to $1 / 3200$ to generate a standard curve was included on each plate. The cut off for positivity was the mean +2 SD of 30 patients who were histologically negative for $H$ pylori and seronegative by western blotting.

\section{HELICOBACTER PYLORI CULTURE}

Biopsy specimens were inoculated on to Skirrow blood agar and cultured for $3-5$ days at $37^{\circ} \mathrm{C}$. The bacteria were identified as $H$ pylori by colony morphology, and positive oxidase, catalase, and urease reactions. The clone picked strains were suspended in $1 \mathrm{ml}$ PBS ( $\mathrm{pH} \mathrm{7.6)} \mathrm{for}$ DNA preparation.

DNA PREPARATION AND PCR ASSAY FOR CagA Aliquots of bacteria $(1 \mathrm{ml})$ were centrifuged at $10000 \times g$ for five minutes. The supernatant was discarded and the bacterial pellet was digested with 0.3 units of proteinase $\mathrm{K}$ at $55^{\circ} \mathrm{C}$ for two hours. DNA was extracted using phenol/chloroform/isoamylalcohol and precipitated. The concentration and quality of DNA samples were estimated by measuring A260/A280. The presence of cagA was determined by polymerase chain reaction (PCR) as described previously. ${ }^{26}$ Briefly, 35 cycles of PCR including 40 seconds of denaturation at $94^{\circ} \mathrm{C}, 40$ seconds of annealing at $50^{\circ} \mathrm{C}$, and 60 seconds of polymerisation at $72^{\circ} \mathrm{C}$ were performed using a pair of primers: $5^{\prime}$-GAT AACAGGCAAGCTTTTGAGG-3' and 5'CTGCAAAAGATTGTTTGCGAGA-3'. The final cycle included an extension step for 10 minutes at $72^{\circ} \mathrm{C}$. Each PCR amplification was performed using a total of $50 \mu \mathrm{l}$ reaction mixture containing $10 \mathrm{mM}$ Tris- $\mathrm{HCl}$ ( $\mathrm{pH} \mathrm{8.3),}$ $50 \mathrm{mM} \mathrm{KCl}, 1.5 \mathrm{mM} \mathrm{MgCl}, 200 \mu \mathrm{M}$ each dNTP, $100 \mathrm{pmol}$ of each primer, 0.5 units Taq polymerase (TaKaRa Taq; Takara Biochemicals, Tokyo, Japan), and $0.1 \mu \mathrm{g}$ of prepared DNA as template. PCR amplification was performed in duplicate for each DNA sample and positive and negative controls were included in each assay. Aliquots $(10 \mu \mathrm{l})$ of each PCR product were analysed by $3 \%$ agarose gel electrophoresis. Results were considered positive when the product, which was equivalent to the fragment described by Peek and colleagues, ${ }^{26}$ was found.

\section{STATISTICAL ANALYSIS}

Odds ratio and $95 \%$ confidence intervals (CI) were calculated by conditional logistic regression analysis in which cases and controls are individually matched. Chi-square analysis was performed to compare the CagA seropositivity between intestinal and diffuse type cancer groups. The two tailed $t$ test was used to compare the titres in the CagA ELISA.

\section{Results}

HELICOBACTER PYLORI STATUS AND HISTOLOGICAL ANALYSIS

$H$ pylori status was evaluated by serology, histology, and bacterial culture (table 1). $H$ pylori positivity by serology, histology, and bacterial culture was $84.0 \%, 82.7 \%$, and $66.7 \%$, respectively, in cancer patients, and $79.0 \%$, $66.7 \%$, and $59.3 \%$, respectively, in control subjects. There was no significant difference in $H$ pylori positivity between cancer patients and control subjects. Histologically, 62 cancers were of the intestinal type and 76 were early gastric cancer. $H$ pylori positivity by serology, histology, and bacterial culture was $82.3 \%$, $80.6 \%$, and $64.5 \%$ in intestinal-type gastric cancer patients, and $89.5 \%, 89.5 \%$, and $73.7 \%$, respectively, in those with diffuse-type gastric cancer. H pylori infection was defined as negative if all of the three tests showed negative results. Seventy cancer patients and 67 control subjects were considered to be $H$ pylori positive. In $67 H$ pylori positive control subjects, the prevalences of glandular atrophy and intestinal metaplasia were $78 \%$ and $35 \%$, respectively. 
Table 1 Patient characteristics and $H$ pylori status

\begin{tabular}{lllllll}
\hline & Mean age (range) & $\begin{array}{l}\text { Sex } \\
(M / F)\end{array}$ & $\begin{array}{l}\text { Stage } \\
(\text { E/A })\end{array}$ & Serology positive & Histology positive & Culture positive \\
\hline Cancers & $62.5(43-85)$ & $50 / 31$ & $76 / 5$ & $84.0 \%(68 / 81)$ & $82.7 \%(67 / 81)$ & $66.7 \%(54 / 81)$ \\
Intestinal & $63.0(44-85)$ & $43 / 19$ & $59 / 3$ & $82.3 \%(51 / 62)$ & $80.6 \%(50 / 62)$ & $64.5 \%(40 / 62)$ \\
Diffuse & $60.7(43-73)$ & $7 / 12$ & $17 / 2$ & $89.5 \%(17 / 19)$ & $89.5 \%(17 / 19)$ & $73.7 \%(14 / 19)$ \\
Controls & $61.8(42-86)$ & $50 / 31$ & & $79.0 \%(64 / 81)$ & $66.7 \%(54 / 81)$ & $59.3 \%(48 / 81)$ \\
\hline
\end{tabular}

E, early stage; A, advanced stage.

Table 2 Helicobacter pylori positivity and CagA seropositivity

\begin{tabular}{lll}
\hline & H pylori positive & CagA positive \\
\hline Cancers & $86.4 \%(70 / 81)$ & $70.0 \%(49 / 70)$ \\
Diffuse & $89.5 \%(17 / 19)$ & $70.6 \%(12 / 17)$ \\
Intestinal & $85.5 \%(53 / 62)$ & $69.8 \%(37 / 53)$ \\
Controls & $82.7 \%(67 / 81)$ & $53.7 \%(36 / 67)$
\end{tabular}

^At least one of serology, histology, or culture was positive.

\section{CagA SEROPOSITIVITY}

CagA seropositivity in cases and controls is shown in table 2 . Sixty per cent (49 of 81 ) of cancer patients and 44\% (36 of 81) of controls were CagA seropositive. In the $H$ pylori negative cancers and controls, CagA seropositivity was observed only in one control subject. The odds ratio for the risk of gastric cancer if CagA seropositive was 1.93 (95\% CI 1.01 to 3.68; $\mathrm{p}=0.041)$. No difference was seen between the two types of carcinoma in CagA seropositivity, $60 \%$ of patients with intestinaltype cancer and $63 \%$ of patients with diffusetype cancer were CagA seropositive. Among the CagA seropositive subjects, titres were similar in the two groups. In the $H$ pylori positive cancer patients and controls, CagA seropositivity was $70 \%$ (49 of 70 ) and $54 \%$ (36 of 67 ), respectively (table 2). In 57 of the $70 \mathrm{H}$ pylori positive patients with gastric cancer, the matched control was also $H$ pylori positive. In the $H$ pylori positive cancer patients and matched controls, CagA seropositivity was $74 \%$ (42 of 57) and $53 \%$ (30 of 57), respectively. The odds ratio for the risk of gastric cancer in $H$ pylori positive patients if CagA seropositive was 2.2 (95\% CI 1.04 to 4.65 ; $\mathrm{p}=0.039)$.

In $H$ pylori positive subjects, there was no difference in IgG antibody titres to conserved $H$ pylori antigens (HELpTEST) in the CagA seropositive and seronegative groups.

\section{SENSITIVITY OF THE CagA ELISA}

$H$ pylori strains isolated from 40 cancer patients and 40 controls were randomly selected to be tested for the presence of cagA by PCR. All of the strains tested from the cancer patients were cagA positive. Twenty nine of these patients were CagA seropositive and the sensitivity of the CagA ELISA in the cancer patients was therefore $72.5 \%$. In the control subjects, 36 of $40 \mathrm{H}$ pylori strains were cagA positive. Thirty of these 36 control subjects were CagA seropositive. The sensitivity of the CagA ELISA was $83.3 \%$ in the control group for detecting cagA infection. The four controls with negative PCR results were seronegative for CagA antibodies.

\section{Discussion}

This is the first study to investigate the association between gastric cancer and CagA sero- positivity by a case control study using individually sex and age matched control subjects who had undergone endoscopy. The results show that CagA seropositivity is associated with increased risk of gastric cancer in an indigenous Japanese population, consistent with previous studies in North American, ${ }^{19}$ European, ${ }^{27}$ and emigrant Japanese patients. ${ }^{18}$ Recently, considerable interest has focused on the strain diversity of $H$ pylori. Many studies have shown that cagA positive strains are more virulent than cagA negative strains and that infection of cagA positive strains results in a more intense gastritis. ${ }^{11-14}$ In part, this is likely to result from the triggering of epithelial chemokine responses, which is dependent on multiple genes in the cag pathogenicity island..$^{10}$ Reactive oxygen and nitrogen species released as a consequence of the inflammation contribute to epithelial cell injury and DNA damage. Correa et al suggested that epithelial cells with DNA damage too extensive to repair may undergo apoptosis, and that the loss of glands in atrophic gastritis may result from large scale induction of apoptosis as the result of such DNA damage. ${ }^{28}$ Infection with cagA positive strains is considered to be associated with increased risk of atrophic gastritis and gastric cancer. ${ }^{16-19}$

Few studies have investigated the relation between infection with CagA and/or VacA positive strains and gastric cancer in Japanese populations that have high incidences of gastric cancer. ${ }^{29-31}$ Kikuchi et al investigated CagA seropositivity in Japanese gastric cancer patients under the age of 40, together with age matched controls. ${ }^{30}$ They showed lack of an association between CagA seropositivity and gastric cancer, conflicting with our results, but many of these young patients had diffuse gastric cancer. Previous studies ${ }^{18} 19$ reported that although CagA seropositivity was associated with increased risk of intestinal-type gastric cancer, there was no association with the diffuse type of gastric cancer. In a North American population, the odds ratio was 3.3 for the risk of gastric cancer in $H$ pylori positive subjects if CagA seropositive. ${ }^{19}$ This odds ratio is similar to the results obtained in the present study in a Japanese population and an earlier study in emigrant Japanese. ${ }^{18}$

We also investigated the sensitivity of the CagA ELISA for detecting infection with CagA positive strains in Japanese patients with and without cancer. The sensitivities of the assay were $72.5 \%$ in cancer patients and $83.3 \%$ in controls. The patients in this study had a mean age of 62 years and the sensitivity of $H$ pylori ELISA is known to be lower in the elderly. ${ }^{32}$ Higher sensitivity in the CagA ELISA has been observed in younger patient groups (Crabtree 
JE, unpublished data, 1997). Although there was no significant difference in the CagA ELISA sensitivity between cancer patients and controls, our results suggest that an underestimation of CagA infection may occur in cancer patients. Extensive intestinal metaplasia will reduce bacterial load and this may well influence systemic immune responses to $H$ pylori. Patients with gastric cancer can have a gastric IgA response to $H$ pylori in the absence of systemic IgG antibodies to $H$ pylori. ${ }^{27}$ In some cancer patients, secondary events associated with cancer might also contribute to false negative serological results. Despite the reduced sensitivity of the ELISA in cancer patients, CagA seropositivity was associated with increased risk of gastric cancer.

In this study, $H$ pylori positivity by histology and culture in cancer patients was much higher than that reported in a recent European study. ${ }^{33}$ In another study, there was a higher rate of histologically detectable $H$ pylori in early than in advanced gastric cancer, suggesting a loss of infection in advanced cancer. ${ }^{34}$ We also found a higher rate of $H$ pylori positivity by both serology and bacterial culture in early than in advanced gastric cancer (unpublished data, 1998). Therefore, it is likely that the high percentage of $H$ pylori positivity in cancer patients seen in this study reflects the high proportion of patients with early stage gastric cancer.

In conclusion, our case controlled study shows that CagA seropositivity is associated with increased risk of gastric cancer in a Japanese population. These results support the concept that infection by strains with the cag pathogenicity island is relevant to inflammation in the gastric mucosa and to the gastric oncogenic process.

We thank Dr Y Saito for preparing $H$ pylori strains, Professor D Forman for his statistical advice and analysis, and Mrs S Perry for her technical assistance. Work in our laboratory is for her technical assistance. Work in our laboratory is undertaken with financial support from the Yorkshire Cancer Research Campaign, European Commission (contract number
IC18CT950024), and the Northern and Yorkshire Regional IC18CT950024),

1 Kuipers EJ, Uyterlinde AM, Pena AS, et al. Long-term

Kuipers EJ, Uyterlinde AM, Pena AS, et al. Long-term sequelae of $\mathrm{H}$

2 Siurala M, Sipponen P, Kekki M. Chronic gastritis: dynamic and clinical aspects. Scand $\mathcal{F}$ Gastroenterol 1985;20(suppl 109):69-76.

3 Imai T, Kubo T, Watanabe H. Chronic gastritis in Japanese with reference to high incidence of gastric carcinoma. $\mathcal{F}$ Natl Cancer Inst 1971;47:179-95.

4 Parsonnet J, Friedman GD, Vandersteen DP, et al. Helicobacter pylori infection and the risk of gastric carcinoma. N Engl f Med 1991;325:1127-31.

5 Nomura A, Stemmermann GN, Chyou P, Kato I, Pérez-Pérez GI, Blaser MJ. Helicobacter pylori infection and gastric carcinoma in a population of Japaneseand gastric carcinoma in a population of Japane

6 Forman D, Newell DG, Fullerton F, et al. Association between infection with Helicobacter pylori infection and risk of gastric cancer: evidence from a prospective risk of gastric cancer: evidence
investigation. $B M \mathcal{F} 1991 ; 302: 1302-5$.

7 Taylor DN, Blaser MJ. The epidemiology of Helicobacter pylori infection. Epidemiol Rev 1991;13:42-59.

8 Covacci A, Censini S, Bugnoli M, et al. Molecular characterization of the $128-\mathrm{kDa}$ immunodominant antigen of Helicobacter pylori associated with cytotoxicity and duodenal ulcer. Proc Natl Acad Sci USA 1993;90:5791-5.

9 Tummuru MKR, Cover TL, Blaser MJ. Cloning and expression of a high-molecular-mass major antigen of Helicobacter pylori: evidence for linkage to cytotoxin production. Infect Immun 1993;61:1799-809.

10 Censini S, Lange C, Xiang Z, et al. cag, a pathogenecity island of Helicobacter pylori, encodes type I-specific and disease-associated virulence factors. Proc Natl Acad Sci USA 1996;93:14648-53.

11 Crabtree JE, Farmery SM. Helicobacter pylori and gastric mucosal cytokines: evidence that CagA-positive strains are more virulent. Lab Invest 1995;73:742-5.

12 Crabtree JE, Taylor JD, Wyatt JI, et al. Mucosal IgA recognition of Helicobacter pylori $120 \mathrm{kDa}$ protein, peptic ulceration, and gastric pathology. Lancet 1991;338:332-5.

13 Peek RM, Miller GG, Tham KT, et al. Heightened inflammatory response and cytokine expression in vivo to cagA+ Helicobacter pylori strains. Lab Invest 1995;73:76070 .

14 Yamaoka Y, Kita M, Kodama T, Sawai N, Imanishi J. Helicobacter pylori cagA gene and expression of cytokine messenger RNA in gastric mucosa. Gastroenterology 1996;110: senger RNA 1742 .

15 Crabtree JE. Gastric mucosal inflammatory responses to Helicobacter pylori. Aliment Pharmacol Ther 1996;10(suppl 1):29-37.

16 Kuipers EJ, Pérez-Pérez GI, Meuwissen SGM, Blaser MJ. Helicobacter pylori and atrophic gastritis: importance of the cagA status. F Natl Cancer Inst 1995;87:1777-80.

17 Beales ILP, Crabtree JE, Scunes D, Covacci A, Calam J. Antibodies to CagA protein are associated with gastric atrophy in Helicobacter pylori infection. Eur 7 Gastroenterol Hepatol 1996;8:645-9.

18 Blaser MJ, Pérez-Pérez GI, Kleanthous H, et al. Infection of strains possessing cagA is associated with an increased risk of developing adenocarcinoma of the stomach. Cancer Res 1995;55:2111-5.

19 Parsonnet J, Friedman GD, Orentreich N, Vogelman H. Risk for gastric cancer in people with CagA positive or CagA negative Helicobacter pylori infection. Gut 1997;40: 297-301.

20 Kimura K, Takemoto T. An endoscopic recognition of the atrophic border and its significance in chronic gastritis. Endoscopy 1969;1:87-97.

21 Lauren P. The two histological main types of gastric carcinoma: diffuse and so-called intestinal-type carcinoma. Acta Pathol Microbiol Scand 1965;64:31-49.

22 Kodama A, Inokuchi K, Soejima K, Matsusaka T, Okamura T. Growth patterns and prognosis in early gastric carcinoma. Cancer 1983;51:320-6.

23 Schembri MA, Lin SK, Lambert JR. Comparison of commercial diagnostic tests for Helicobacter pylori antibodies. F Clin Microbiol 1993;31:2621-4.

24 Yamamoto I, Fukuda Y, Mizuta T, et al. Evaluation of nine commercial serodiagnostic kits for the detection of Helicobacter pylori infection in Japan. Res For Dig Dis 1994;1:7585.

25 Xiang Z, Bugnoli M, Ponzetto A, et al. Detection in an enzyme immunoassay of an immune response to a recombinant fragment of the 128 kilodalton protein $(\mathrm{CagA})$ of Helicobacter pylori. Eur 7 Clin Microbiol Infect Dis 1993;12: $739-45$.

26 Peek RM, Miller GG, Tham KT, et al. Detection of Helicobacter pylori gene expression in human gastric mucosa. $\mathcal{F}$ Clin Microbiol 1995;33:28-32.

27 Crabtree JE, Wyatt JI, Sobala GM, et al. Systemic and mucosal humoral responses to Helicobacter pylori in gastric cancer. Gut 1993;34:1339-43.

28 Correa P, Miller MJ. Helicobacter pylori and gastric atrophy-cancer paradoxes. F Natl Cancer Inst 1995;87: 1731-2.

29 Hirai M, Azuma T, Ito S, Kato T, Kohli Y, Fujiki N. High prevalence of neutralizing activity to Helicobacter pylori prevalence of neutralizing activity to Helicobacter pylori
cytotoxin in serum of gastric-carcinoma patients. Int 7 cytotoxin in serum of

30 Kikuchi S, Forman D, Covacci A, Crabtree JE. Diffuse gastric cancer in young $\mathrm{H}$. pylori positive Japanese patients: ack of association with CagA status. Gut 1996;39(suppl 2):A68

31 Ito S, Azuma T, Murakita $\mathrm{H}$, et al. Profile of Helicobacter pylori cytotoxin derived from two areas of Japan with different prevalence of atrophic gastritis. Gut 1996;39:800-6.

32 Crabtree JE, Shallcross TM, Heatley RV, Wyatt JI Evaluation of a commercial ELISA for serodiagnosis of Helicobacter pylori infection. $\mathcal{F}$ Clin Pathol 1991;44:326-8

33 Menegatti M, Vaira D, Holton J, et al. Serological response to Helicobacter pylori in gastric and non-gastric cancer. Clin Sci 1996;91:219-23.

34 Caruso ML, Fucci L. Histological identification of in Helicobacter pylori early and advanced gastric cancer. $\mathcal{F}$ Clin Gastroenterol 1990;12:601-2. 